\title{
Review
}

\section{Blood glucose levels in diabetic and non-diabetic subjects*}

\author{
Georges Tchobroutsky \\ Hôtel-Dieu, Université Pierre et Marie Curie, Paris, France
}

Most, if not all, diabetologists are convinced, on the basis of indirect evidence which has been accumulated over the decades that the microangiopathic and neurological complications of diabetes are primarily dependent on the duration and extent of chronic hyperglycaemia [1-5]. Hyperglycaemia is the necessary factor in the development of these complications even if other, secondary factors, sometimes responsive to treatment, such as blood pressure levels, smoking, protein intake, with or without genetic predisposition, may modulate its expression [6]. However, as emphasized by Krolewski et al. [7] and Mogensen [8] it is the degree (and duration) of hyperglycaemia which remains the most important aetiological factor in predisposed groups of patients.

Before we are able to detect with accuracy on an individual basis the subjects at risk from diabetic complications, blood glucose control will be of paramount importance because, as emphasized by Rothman [9]:

\begin{abstract}
"Identification of all the components of a given sufficient cause is unnecessary for prevention, in that blocking the causal role of but one component of a sufficient cause renders the joint action of the other components insufficient and prevents the effect."
\end{abstract}

Among the advice given to an insulin-treated diabetic patient that which is related to glucose control is aiming to try to normalize blood glucose levels. Regarding blood glucose control we will discuss briefly the following points: What are "normal", fasting and post-prandial blood glucose levels? What are fasting and post-prandial blood glucose levels of insulin-treated diabetic patients? What are the limiting factors to the normalization of blood glucose levels in diabetic patients? How high is high? (harmfulness of hyperglycaemia), and How to advance presentday treatment?

\footnotetext{
* 1989 Claude Bernard Lecture of the European Association for the Study of Diabetes delivered in Lisbon on September 1989
}

\section{"Normal" fasting blood glucose levels}

It is wise, firstly, to question the meaning of the word normal. Table 1 lists, according to Murphy [10-12], the situations in which the word "normal" is used and the preferable term (the choice of which depends on the goal).

Amidst the seven meanings proposed by this methodologist one is of particular importance for the epidemiologist: i. e. the reference value, namely that obtained from a population considered healthy and serving as reference. Another is probably much more useful in individual medical practice and is that which defines the norm as nonpathogenic and the abnormal as dangerous to one's health. A famous example well illustrates these points: when a group of European researchers, working on urinary bilharzia, asked the chief of a sub-tropical village to gather all his subjects presenting abnormal urines in the main square, only three appeared, their urine was perfectly limpid and the "normal" population was that which had red urine and was ill.

Fasting plasma glucose levels are unimodally distributed within apparently non-diabetic adult populations except in a few highly inbred communities in Arizona and the South Pacific. In the French telecommunications adult employee population of 3220 adults studied by my colleague D. Simon and his collaborators [13] $95 \%$ of the values obtained regardless of sex, and age, are below $106 \mathrm{mg}$ per $100 \mathrm{ml}$ i.e. $5.8 \mathrm{mmol} / \mathrm{l}$ (Table 2). According to Gaspart [14] the distribution of blood glucose values in a general population is asymmetric with a tail towards higher values and is true for both sexes.

Fasting plasma glucose in apparently non-diabetic subjects tends to rise with age [13-15]. The younger the subjects the more their blood sugar levels are distributed below $5.5 . \mathrm{mmol} / 1$ (Table 2).

Fasting glycaemia is lower in pre-menopausal women than in men $[13,16]$ (Table 2). We have also shown that natural oestrogen administration decreases fasting blood glucose levels in young healthy men [17].

The fact that pre-menopausal women have lower fasting blood glucose levels than men is an important fact to 
Table 1. Murphy's seven meanings for "normal"

\begin{tabular}{lll}
\hline Paraphrase & Where used & Preferable term \\
\hline 1. Probability function (bell-shaped curve) & Statistics & Gaussian \\
2. Most representative of its class & Descriptive sciences & Average, median, mod. \\
3. Commonly encountered in its class & Descriptive sciences & Habitual \\
4. Most suited to survival & Genetics, operations research & Optimal, "fittest" \\
5. Carrying no penalty & Clinical medicine & Innocuous, harmless \\
6. Commonly aspired to & Politics, sociology & Conventional \\
7. Most perfect of its class & Metaphysics, esthetics, morals & Ideal \\
\hline
\end{tabular}
[10-12]

Table 2. Fasting plasma glucose by age, sex and menopausal status in the adult telecom population

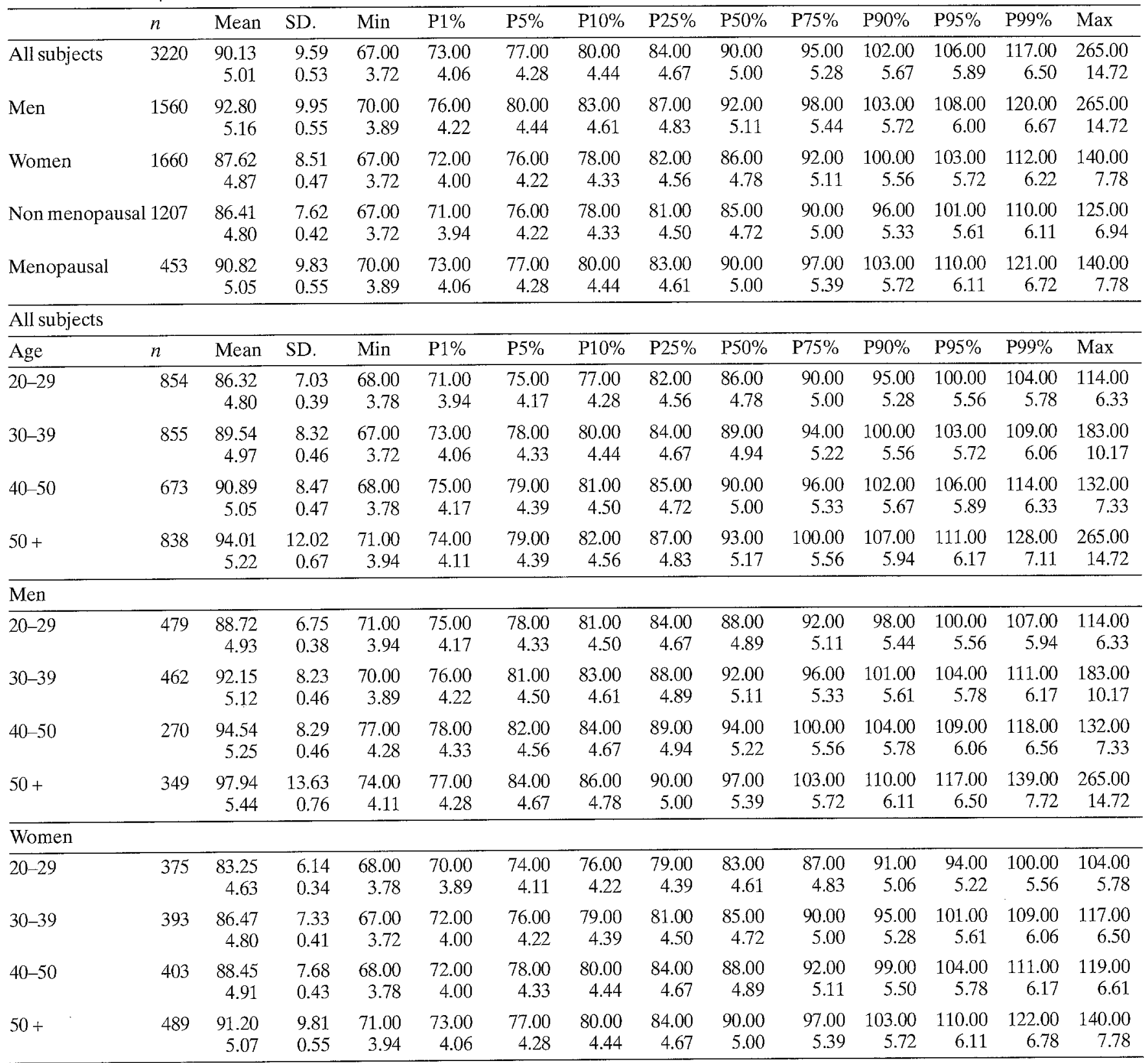


Table 3. Venous plasma glucose levels ( $\mathrm{mg} / \mathrm{dl}$ and $\mathrm{mmol} / \mathrm{l}$ ) in 244 pregnant non-diabetic women at 33-37 weeks of pregnancy and no diabetic risk factors

\begin{tabular}{lcllll}
\hline & Mean & SD & Range & \\
\hline Fasting & 80 & 8 & $55-108$ & $98.4 \%$ & $<100 \mathrm{mg} / \mathrm{ml}$ \\
& 4.4 & 0.4 & $3.0-6$ & $<5.5 \mathrm{mmol} / 1$ \\
Post meal & 90 & 16 & $60-150$ & $97.5 \%$ & $<126 \mathrm{mg} / \mathrm{ml}$ \\
(not-standardized) & 5 & 0.8 & $3.3-8.3$ & $<7 \mathrm{mmol} / \mathrm{l}$ \\
\hline
\end{tabular}

Unpublished data from C.Tchobroutsky and M. Vray, Maternity University Hospital of Port-Royal (Paris) and INSERM U. 21 (Villejuif)

consider when carrying out a fasting test period for the diagnosis of spontaneous hypoglycaemia. During a fasting state blood glucose levels decrease more in pre-menopausal women than in men or post-menopausal women [16].

Fasting plasma glucose values in non-diabetic pregnant women have also been studied. Unpublished data from the Maternity University Hospital of Port-Royal have shown that $98.4 \%$ of the fasting values are below $5.5 \mathrm{mmol} / \mathrm{l}$ in healthy pregnant women with no diabetic risk factors at 33-37 weeks gestation (Table 3). Farmer and colleagues studied 917 pregnant non-diabetic women at 32 weeks gestation: $97.5 \%$ of the values observed were below $5.2 \mathrm{mmol} / \mathrm{l}[18]$. Thus, it appears that in non-diabetic pregnant women fasting blood glucose values are much lower than those often considered as "normal" at least on the highly specific criteria required by some authors for the determination of glycaemic abnormalities during pregnancy [19].

As is perfectly known, reference values include, when the distribution is unimodal, some subjects in the upper percentiles who are already ill or at high risk of becoming ill. The upper tail of these unimodal distributions sometimes shows surprisingly high values in supposed "healthy" populations used as reference $[14,15]$. Although this might be due to bias in the selection of the subjects.

Epidemiologists try to set up classifications which are simply tools for longitudinal studies or for comparison between groups and populations. In borderline cases definitions and classifications must not be interpreted as clues for individual diagnosis of diabetes or non-diabetes. Unfortunately despite constant warnings, particularly from the WHO expert committee [20], these arbitrary figures, neither sacrosanct nor eternal, are currently used for clinical practice or clinical studies leading to misleading titles and conclusions. The important issue is to know whether a slightly increased blood glucose level (e.g. above the 95th percentile in young subjects of above the 97.5 th in elderly patients of the reference population) is the hallmark of diabetes or just one of the several markers (risk factors) of possible future diabetes mellitus as are other better known markers.

\section{"Normal” post-prandial blood glucose levels}

Few studies have been devoted to defining normal postprandial blood glucose values. When they were done they usually concerned very small groups of subjects and were restricted to the midday meal with the exception of a 1976 study [21] and two non-standardized very large epidemiological studies [22, 23].

In 1970 we performed a study concerning 8 healthy subjects and 16 diabetic patients who consumed a standardized $880 \mathrm{kcal}$ meal containing $90 \mathrm{~g}$ of carbohydrate [22]. All these normal, 20- to 40-year-old, adult subjects maintained their maximal post-prandial blood glucose levels on this standardized meal below $6 \mathrm{mmol} / \mathrm{l} 2 \mathrm{~h}$ after the beginning of the meal.

We later studied the variations in glycaemia 45 to $120 \mathrm{~min}$ following a midday non-standardized meal in 110 non-diabetic subjects 45 of whom were apparently healthy and 65 who presented with non-metabolic diseases [23]. The increments in post-prandial plasma glycaemias were extremely small.

Non-standardized post-prandial blood glucose levels rise with age according to the formula: second hour blood glucose $=0.516 \times$ years $+88.2(\mathrm{in} \mathrm{mg} / \mathrm{dl})[23]$.

From the Port-Royal Maternity Hospital data it appears that post-prandial plasma glucose levels remain at a low level during pregnancy, even close to delivery since $97.5 \%$ of the values remain below $7 \mathrm{mmol} / \mathrm{l}$ between $1 \mathrm{~h}$ $30 \mathrm{~min}$ and $2 \mathrm{~h}$ post cibum (Table 3 ).

\section{Blood glucose levels in insulin-treated patients}

Despite our efforts directed towards the ideal achievement of normalised blood glucose levels it is obvious that in Type 1 (insulin-dependent) diabetic patients, treatment remains far from optimal and blood glucose levels, in terms of means, never really attain the values observed in the reference populations.

a) Pregnancy might be the best example to show, on the one hand, the progress we can achieve with routine treatment and, on the other, our limitations. This condition also serves to draw attention to an area in which there is general consensus as to the need for the best possible glycaemic control [24]. From unpublished data on 389 pregnancies in Type 1 diabetic patients conjointly followed with the Maternity Hospital of Port-Royal it appears that between 1971 and 1977 fasting and post-prandial blood sugar levels were never normalized in terms of means and that after 1978, despite technological advances in diabetology and obstetrics the values have, if anything, become worse: the blood glucose levels at entry and at 32 weeks were as follows: during the 1971-1977 period mean fasting plasma glucose $(\mathrm{mmol} / \mathrm{l}$, mean $\pm \mathrm{SD})$ was $8.2 \pm 4.3$ in the first trimester and $6.3 \pm 2.8$ at 32 weeks. Post-prandial levels ( $1 \mathrm{~h} 30 \mathrm{~min}$ to $2 \mathrm{~h}$ after the beginning of the main meal) were $6.6 \pm 3.3$ and $5.8 \pm 2.5$, respectively. In the second period, the following values were found: fasting: $8.1 \pm 4.2$ in the first trimester; $8.0 \pm 2.8$ at 32 weeks; postprandial: $7.9 \pm 2.8$ in the first trimester and $7.1 \pm 3.1$ at 32 weeks. These differences were significant for fasting plasma values at 32 weeks $(p<0.001)$, post-prandial levels in the first trimester $(p<0.001)$ and at 32 weeks $(p<0.001)$. This may in fact be due to recent technological advances which have released both doctors and pa- 
Table 4. Amniotic fluid concentrations of glucose, insulin and Cpeptide related to gestational age

\begin{tabular}{llll}
\hline Duration of pregnancy (weeks) & $<32$ & 32 to 35 & $\geqslant 36$ \\
\cline { 1 - 2 } Glucose $(\mathrm{mg} / 100 \mathrm{ml})$ & 30 & $24 \pm 2$ & $22 \pm 4$ \\
$\quad$ Normal & $(1)$ & $(10)$ & $(13)$ \\
Diabetics & - & $53 \pm 6$ & $42 \pm 6$ \\
& - & $p<0.01$ & $p<0.05$ \\
& & & \\
Insulin $(\mu \mathrm{U} / \mathrm{ml})$ & 2 & $6 \pm 1$ & $7 \pm 1$ \\
$\quad$ Normal & $(1)$ & $(11)$ & $(15)$ \\
& - & $15 \pm 2$ & $25 \pm 7$ \\
Diabetics & $(0)$ & $(17)$ & $(27)$ \\
& - & $p<0.01$ & $p<0.01$ \\
& & & \\
C-peptide $(\mathrm{ng} / \mathrm{ml})$ & 1.6 & $1.4 \pm 0.3$ & $1.3 \pm 0.2$ \\
Normal & $(1)$ & $(10)$ & $(14)$ \\
& - & $2.5 \pm 0.3$ & $2.3 \pm 0.4$ \\
Diabetics & $(0)$ & $(15)$ & $(21)$ \\
& - & $p<0.05$ & $p<0.06$ \\
\hline
\end{tabular}

Number of subjects shown in parentheses. Results given as mean \pm SEM [31]

Table 5. Values of mean fasting (F) and post prandial (PP) blood glucose and haemoglobin $\mathrm{A}_{\mathrm{lc}}\left(\mathrm{HbA}_{\mathrm{lc}}\right)$ levels for the insulin dependent diabetic patients

\begin{tabular}{lcccl}
\hline Centers & W & $\mathrm{X}$ & $\mathrm{Y}$ & $\mathrm{Z}$ \\
$n=$ & 95 & 63 & 51 & 44 \\
\hline $\mathrm{FBG} \mathrm{mg} / \mathrm{dl}$ & $146 \pm 74$ & $149 \pm 78$ & $235 \pm 117$ & $227 \pm 10$ \\
$\mathrm{mmol} / \mathrm{l}$ & $8.1 \pm 4.1$ & $8.3 \pm 4.3$ & $13.0 \pm 6.5$ & $12.6 \pm 5.5$ \\
$\mathrm{PP} \mathrm{BG} \mathrm{mg/dl}$ & $175 \pm 85$ & $215 \pm 105$ & $205 \pm 103$ & - \\
$\mathrm{mmol} / \mathrm{l}$ & $9.7 \pm 4.7$ & $11.9 \pm 5.8$ & $11.4 \pm 5.7$ & - \\
$\mathrm{HbA}_{1 \mathrm{c}} \%$ & $7.7 \pm 1.7$ & $8.2 \pm 1.4$ & $10.6 \pm 2.0$ & $11.3 \pm 1.8$ \\
\hline
\end{tabular}

Unpublished data from the Damad Study [34]

tients from anxiety. Despite these changes in glycaemic control beneficial effects have been obtained in premature deliveries and in the number of Caesarian deliveries without change in perinatal mortality. This is due to the desirability of carrying the pregnancy as close as possible to full term. However, even when corrected by the later term, it appears that although mean birthweights have risen significantly the numbers of malformations remain the same.

Examples from the literature indicate than even in the most motivated of health-care systems, the percentage of well controlled patients is feeble apart from a few experimental studies, where enormous efforts have been made by practitioners such as Loïs Jovanovic and her colleagues [25] or Reversi et al. [26]. In general what is obtained is a mean glycaemic control which is at best, 30 to $40 \%$ over reference values. Data from Chicago [27] where definition of good control is empirical and reasonable, but where normoglycaemia is not achieved, showed that at the beginning of the pregnancy only $27 \%$ of pregnant women had what was considered to be good glucose control. This number rises to $62 \%$ from week 32 onwards. The author's aim was to show that the frequency of large for gestational age infants was conditioned by the metabolic control achieved before week 31 and not by that of the last trimester. Data presented by the late Ivo Drury in his Banting lecture [28], based on glycated haemoglobin values (given along with their reference values) showed that $38 \%$ of the women followed in Dublin had $\mathrm{HbA}_{1 \mathrm{c}}$ values within the normal reference range throughout the third trimester. The higher the glyco-haemoglobin values the heavier the children were (birthweight being corrected by gestational age).

These data, including ours, cover the last 15 to 20 years. But results are no better in a recent multicentre study done in the USA [29].

With reference to some consequences of this lack of normalisation of blood glucose in terms of means during pregnancy Farmer et al. [18] remark upon the fact that in reference populations where the fasting blood glucose levels and other parameters are in the lower normal range, birthweight and subcutaneous skin thickness in particular depend closely on "normal" maternal blood glucose levels. As British authors have pointed out, birthweight values are distributed along Gaussian distributions in reference as well as in diabetic populations [30]. One can probably extend this causal relationship between glycaemia and weight from children of nondiabetic mothers to those of diabetic women who, due to our sub-optimal therapeutic conditions, are statistically and inexorably overweight for their term. Whether it is dangerous or not, whether it increases the number of Caesarian deliveries or induces increased mortality in these children are questions I will not discuss but it is highly probable that all these risks are linearly related to maternal blood glucose levels without clear pathogenic cut-off points.

Table 4 shows the data we obtained in 1980 [31] concerning changes in the fetus as reflected in changes in amniotic fluid from diabetic and non-diabetic mothers. The glucose concentration in amniotic fluid of the diabetic patients was markedly higher than in the control subjects, before and after 36 weeks of gestation. This was responsible for an increased insulin-secretion in the child assessed on C-peptide levels in the amniotic fluid which reached twice those of control subjects. There was a close correlation between C-peptide and glucose concentrations in the amniotic fluid $(p<0.05)$ and the infant's birthweight $(p<0.01)$ (even after correction for gestational age) $(p<0.05)$.

b) Blood glucose levels in the general non-pregnant Type 1 diabetic population. Data from Düsseldorf, Vienna and Bucharest [32] showed that $\mathrm{HbA}_{i c}$ values in Type 1 diabetic patients obtained with routine, yet highly-structured teaching and care systems were identical to those observed in so-called highly intensive research conditions. Thus, improvements are possible when healthcare management is structured and when methods using either multiple injections or continuous insulin infusion by pumps are implemented. The best that can be achieved in terms of means is as in pregnancy $\mathrm{Hb}$ values 30 to $40 \%$ above mean reference values. Less than 10 years ago we carried out a cross-sectional study in in- 


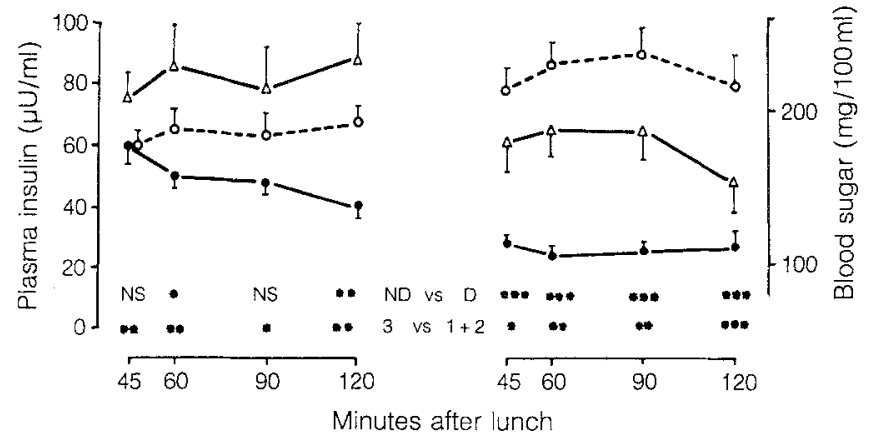

Fig. 1. Post prandial blood sugar (right) and plasma insulin (left) levels in 38 non-diabetic and 30 Type 1 (insulin-dependent) diabetic subjects $O$. Values are mean \pm SEM. Values for the 14 patients treated by 3 daily injections of insulin are given separately $\triangle$. $\mathrm{NS}=$ non significant; $*=p<0.05 ; * *=\mathrm{p}<0.01 ; * * *=p<0.001$; (based on data from Tchobroutsky et al. [36])

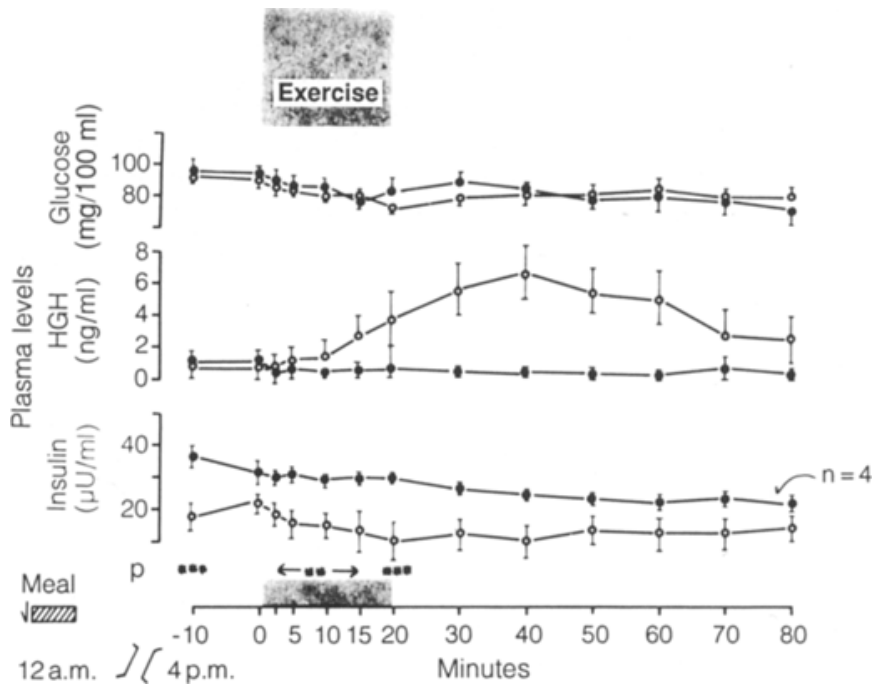

Fig.2. Plasma levels of glucose, human growth hormone (HGH) and insulin before, during and after exercise in seven healthy $O$ and six insulin-treated - diabetic men. Values are means $\pm S E M$. Before and during exercise the mean plasma insulin values are significantly higher in the diabetic than in the healthy subjects at times: $-10,2.5,5,10,15$ and $20 \mathrm{~min}$. ${ }^{* *}=p<0.01$, **** $=p<0.001$. (From G. Tchobroutsky et al. [39])

sulin-treated diabetic out-patients [33]. Only $19 \%$ of all the diabetic patients had $\mathrm{HbA}_{1 \mathrm{c}}$ levels less than $3 \mathrm{SD}$ above the mean reference value. But the percentage of subjects in whom $\mathrm{HbA}_{1 \mathrm{c}}$ values could be considered as acceptable was $33 \%$ in those receiving three daily injections (usually fast-acting regular insulin before each meal associated with intermediate insulin either at bedtime or with the evening meal). As for post-prandial blood glucose values collected randomly 1 to $2 \mathrm{~h}$ after the beginning of a non-standard meal, it appeared that they were very low ("normal") in those who had received regular insulin before the meal. All that is needed is to prescribe the regular insulin! Table 5 shows data from four centres which have participated in a multicentre European trial [34]. Great differences can be seen between the centres in mean fasting and post-prandial glycaemia as in $\mathrm{Hb}$ levels.

\section{Current limitation to blood glucose control in insulin-treated patients}

We are aware of the obstacles facing progress in blood glucose control in Type 1 diabetic patients with our current routine treatments: they are psychological, social and educational in nature but also reflect our inability to mimic native insulin physiology. Indeed, insulin is injected in the wrong place and as has often been said at the wrong time, in the wrong way and in the wrong quantities. Whatever insulin-resistance there may be it appears that the major obstacle is our difficulty or inability to restore physiological portal insulin levels.

After a meal control of glycaemic excursions in nondiabetic subjects depends, in my opinion, essentially on the insulin concentrations obtained in the portal vein and on the speed with which this peak of insulinaemia is reached. After the pioneering work of Blackard and Nelson [35], we studied in 1973 [36] non-diabetic subjects (and also Type 2 (non-insulin dependent)) diabetic patients as we benefitted at that time from the development of per-umbilical access to the portal vein. In non-diabetic subjects, peripheral blood insulin levels decline as early as 30 min following a meal, with an equal fall in portal vein blood levels where concentrations were at least 2 to 4 times higher that the peripheral levels from 60 min onwards.

In Type 1 diabetic patients treated with insulin it is obvious that for physical reasons the systemic venous concentrations achieved by the peripheral administration of insulin are the same as those obtained in the portal vein since insulin is not injected into the portal system. In 1970 and 1973 we attempted to deal with this problem indirectly $[22,36]$ by studying the circulating peripheral exogenous plasma insulin levels in Type 1 diabetic patients. We took well controlled patients treated for less than three or, more often, one month who had previously been hospitalized with severe insulin deprivation presenting with diabetic coma or severe ketosis and in whom the absence of anti-insulin antibodies [37] allowed an estimate of exogenous circulating peripheral insulin levels. Blood glucose levels in treated diabetic patients were extremely high after meals, although less so in those who received three injections of regular insulin per day, but insulin levels were still higher in diabetic patients than in normal subjects, in spite of high concomittant blood sugar levels (Fig. 1). It seems unnecessary, but not to be excluded, to invoke insulin resistance to explain this phenomenon (in fact insulin resistance in Type 1 diabetes is reversible after treatment [38]). In view of the fact that peripheral insulin. levels are also the portal insulin levels of these treated diabetic patients these portal levels are quite obviously insufficient compared to those of non-diabetic subjects.

In order to obtain normalisation of blood glucose levels, it is important to obtain in peripheral venous blood, both before and after meals, insulin levels at least two to three times as high as those observed in the peripheral blood-stream of control subjects as shown in 1974 [39], when we undertook a study to evaluate the secretion of growth hormone during exercise (Fig. 2) (which of course was normal when blood glucose levels were also normal). 
Table 6. Some pioneering studies on the use of regular insulin

\begin{tabular}{llll}
\hline Johnsson & 1960 & Forsham & 1967 \\
Lawrence & 1963 & Pedersen & 1967 \\
Lukens & 1965 & Metz et al. & 1967 \\
Aubertin & 1965 & Earl & 1968 \\
Oakley et al. & 1966 & Service et al. & 1970 \\
Chabanier (in Deuil) & 1967 & Rull et al. & 1970 \\
Tutin et al. & 1967 & Spathis & 1970 \\
& & Vining and Strong & 1972 \\
\hline
\end{tabular}

[45]

What physiology teaches us is that therapy is far from being just that, i.e. physiological, not to mention the peripheral hyperinsulinism we induce.

\section{Danger of high blood glucose levels}

Epidemiological studies have shown that in Type 2 diabetic patients blood glucose levels below $7.8 \mathrm{mmol} / 1$ on fasting and $11.1 \mathrm{mmol} / \mathrm{l}$ after meals may not be harmful to the kidney or the retina $[40,41]$.

Mogensen [42] has emphasised that it could be possible that lesions may remain minimal when $\mathrm{HbA}_{1 c}$ levels are kept within $4 \mathrm{SD}$ of the mean. In a recent longitudinal study from the USA, Chase and colleagues [43] have shown that the risk of developing micro-albuminuria at any age, or the risk of developing any preoccupying retinopathic lesions was proportionally much lower when mean $\mathrm{HbA}_{1 \mathrm{c}}$ values were less than $10 \%$ above the upper normal range. The risk increases rapidly with higher but not necessarily catastrophic $\mathrm{Hb}$ levels.

As mentioned above in the field of obstetrics there is probably no threshold to the deleterious effect of glycaemia but rather a linear relationship between blood glucose levels and macrosomia even in healthy normal women. This may be true for miscarriage as shown by Mills et al. [44] and probably also for congenital malformations.

\section{How to progress in routine conditions of treatment}

So I believe, as do many other diabetologists, that it is very important to improve blood glucose control, as well as other parameters such as blood pressure, in diabetic patients. Even if ideal control cannot be achieved the lower the blood glucose level the better. Perhaps in the near future it will be possible to identify all those diabetic patients at risk of developing complications and focus on them our greatest efforts.

There is now a growing trend, to use regular fast-acting insulin several times a day in conjunction with intermediate insulin, for the night using an insulin pen-injection system. This regimen has been advocated over the last 30 years (Table 6) [45]. At least post-prandial glucose levels can be improved by using regular insulin injections before each meal [23].

The use of regular insulin and the structuring of care and teaching have induced, as we have shown [46] among others, better equilibrium and better results in terms of life-style for diabetic patients. Hypoglycaemic episodes are less frequent and quality of life has been improved by energetic management. Due to the limitations we are faced with, we know that insulin treatment remains imperfect. Short-acting insulins and/or the use of intra-nasal administration of the hormone, even if of some help, will not allow per se physiological treatment. But the impossibility of attaining "normal" plasma glucose levels is not a reason for pessimism. Better is better than bad.

Acknowledgements. I am greatly indebted to the European Association for the Study of Diabetes for the honour of having been selected as 1989 Claude Bernard Lecturer. I also wish to thank the Paul Neuman Foundation. I would like to thank all those who have participated in the studies mentioned in particular G.Rosselin, P.Freychet, R.Assan, M.Hautecouverture, J.Dolais-Kibatchi, E. Eschwege, L.Papoz, N.Thibult, A. Fontbonne, J.Chwalow, D.Simon, F. Elgrably, P.Y.Traynard, H.Selmi, Cl.Goldgewicht, M.Letanoux, G.Reach, D.Charitanski, M.Tutin, A. Basdevant, J.J.Altman, J.Boillot. I am also indebted to my mentors Maurice Derot and Marcel Legrain and to the team of skilled technicians, secretaries and nurses without whom my work would have been impossible: F. Bruzzo, A. Chevallier, N.Desplanques, M.Bros, A. Delage, H.Jacob, F.Leblanc, M.Roman, M.Roulon, N.Klein, M.M.Thiebaut, J.Jacquesson, N.Grenier, A.M. Grapin and particularly Annick Forge. Last, but not least, I would like to thank my alter ego Gerard Slama who has put up with me (and vice versa) for decades.

\section{References}

1. Tchobroutsky G (1978) Relation of diabetic control to development of microvascular complications. Diabetologia 15: 143-152

2. Kilo C (1985) Value of glucose control in preventing complications of diabetes. Am J Med 79A [Suppl 2B]: 33-37

3. Hanssen KF, Dahl-Jorgensen K, Lauritzen T, Feldt-Rasmussen B, Brinchmann-Hansen O, Deckert T (1986) Diabetic control and microvascular complications: the near-normoglycaemic experience. Diabetologia 29: 677-684

4. Leslie ND, Sperling MA (1986) Relation of metabolic control to complications in diabetes mellitus. J Pediatr 108: 491-497

5. Rosenstock J, Raskin P (1986) Early diabetic nephropathy: assessment and potential therapeutic interventions. Diabetes Care 9: 529-545

6. Tchobroutsky G (1989) Why do some diabetics develop severe microvascular complications? J Diabetic Complications $3: 1-5$

7. Krolewski AS, Canessa M, Warram JH, Laffel LMB, Christlieb AR, Knowler WC, Rand LI (1988) Predisposition to hypertension and susceptibility to renal disease in insulin-dependent diabetes mellitus. N Engl J Med 319: 140-145

8. Mogensen CE (1988) Histoire naturelle de la néphropathie diabétique chez le diabétique insulinodépendant et concept d'une intervention non glycémique. In: Journées Annuelles de Diabétologie de l'Hôtel-Dieu. Flammarion Médecine Sciences, Paris, pp 225-246

9. Rothman KJ (1976) Reviews and Commentary: Causes. Am J Epidemiol 104: 587-592

10. Murphy EA (1966) A scientific viewpoint on normalcy. Perspect Biol Med 9: 333-348

11. Galen RS (1977) The normal range. A concept in transition. Arch Pathol Lab Med 101:561-565

12. Galen RS, Gambino SR (1975) Beyond normality. The predictive value and efficiency of medical diagnoses. Wiley \& Sons, New York

13. Simon D, Senan C, Garnier P, Saint-Paul M, Lapoz L (1989) Epidemiological features of glycated haemoglobin $\mathrm{A}_{1 \mathrm{c}}$ distribution in a healthy population. The Telecom study. Diabetologia 32: 864-869 
14. Gaspart E (1985) Glucose. In: Siest G, Henny J, Schiele F, Young DS (eds) Interpretation of clinical laboratory tests. Reference values and their biological variation. Biomedical, Foster City, California, pp 253-269

15. Barrett-Connor E (1980) Factors associated with the distribution of fasting plasma glucose in an adult community. Am J Epidemiol 112: 518-523

16. Selmi A, Hautecouverture M, Basdevant A, Slama G, Tchobroutsky $G$ (1976) Influence du sexe sur la baisse de la glycémie induite par le jeûne court. Diabete Metab 2: 195-198

17. Hautecouverture M, Slama G, Assan R, Tchobroutsky G (1974) Sex related diurnal variations in venous blood glucose and plasma insulin levels. Effects of estrogens in men. Diabetologia 10: $725-730$

18. Farmer G, Russell G, Hamilton-Nicol DR, Ogenbede HO, Ross IS, Pearson DWM, Thom H, Kerridge DF, Sutherland HW (1988) The influence of maternal glucose metabolism on fetal growth, development and morbidity in 917 singleton pregnancies in non-diabetic women. Diabetologia 31: 134-141

19. Position Statement. Gestational diabetes mellitus (1986) American Diabetes Association. Diabetes Care 9:430-431

20. WHO Expert Committee on Diabetes Mellitus (Second Report 1980) Technical Report Series 646, World Health Organization, Geneva

21. Lefebvre PJ, Luyckx AS (1976) The breakfast tolerance test: a return to physiology. Diabete Metab 2: 15-19

22. Tchobroutsky G (1970) Repas-tests chez des sujets normaux et des diabétiques traités. Presse Med 78: 1359-1364

23. Kopf A, Tchobroutsky G, Eschwege E (1973) Serial postprandial blood glucose levels in 309 subjects with and without diabetes. Diabetes 22: 834-846

24. Coustan DR, Berkowitz RL, Hobbins JC (1980) Tight metabolic control of overt diabetes in pregnancy. Am J Med 6: 845-853

25. Jovanovic L, Druzin M, Peterson CM (1981) Effect of euglycemia on the outcome of pregnancy in insulin dependent diabetic women as compared with normal control subjects. Am J Med 71: 921-927

26. Roversi GD, Gargiulo M, Nicolini E, Ferrazi E, Pedretti E, Gruft L, Tronconi G (1980) Maximal tolerated insulin therapy in gestational diabetes. Diabetes Care 3: 489-495

27. Lin CC, River Y, River P, Blix PA, Moawad AM (1986) Good diabetic control early in pregnancy and favorable fetal outcome. Obstet Gynecol 1: $51-56$

28. Drury MI (1989) "They give birth astride of a grave." Diabetic Med 6: 291-298

29. Mills JL, Knopp RH, Simpson JL et al. (1988) Lack of relation of increased malformation rates in infants of diabetic mothers to glycemic control during organogenesis. $N$ Engl J Med 11: 671-676

30. Bradley RJ, Nicolaides KH, Brudenell JM (1988) Are all infants of diabetic mothers "macrosomic"? Br Med J 297: 1583-1584

31. Tchobroutsky G, Heard I, Tchobroutsky C, Eschwege E (1980) Amniotic fluid C-peptide in normal and insulin-dependent diabetic pregnancies. Diabetologia 18: 289-292

32. Mühlhauser I, Bruckner J, Howorka K (1987) Near-normoglycemia and microvascular complications. Diabetologia 30:47-48

33. Tchobroutsky G, Charitanski D, Blouquit Y, Papoz L, Soria J, Rosa J (1980) Diabetic control in 102 insulin-treated out-patients. Diabetologia 18: 447-452
34. The DAMAD Study Group (1989) Effect of aspirin alone and aspirin plus dipyridamole in early diabetic retinopathy. A multicenter randomized controlled clinical trial. Diabetes 38 : $491-498$

35. Blackard WG, Nelson NC (1970) Portal and peripheral vein immunoreactive insulin concentrations before and after glucose infusion. Diabetes 19: 302-305

36. Tchobroutsky G, Kopf A, Eschwege E, Assan R (1973) Serial postprandial plasma insulin levels in 117 subjects with and without diabetes. Diabetes 22: 825-833

37. Rosselin G, Tchobroutsky G, Assan R, Lellouch J, Dolias J, Derot M (1965) Etude quantitative d'anticorps humains anti-insulines animales par la méthode radio-immunologique de Berson et Yalow. Diabetologia 1: 33-38

38. Ferrannini E, Bevelacqua S, Bonadonna R (1987) The insulin resistance of type I diabetes mellitus: an overview. In: Brunetti P, Waldhaüsl WK (eds) Advanced models for the therapy of insulin-dependent diabetes. Serono symposia, vol 37, Raven Press, New York, pp 7-12

39. Tchobroutsky G, Lenormand ME, Michel G, Assan R (1974) Lack of post prandial exercise-induced growth hormone secretion in normoglycemic insulin-treated diabetic men. Horm Metab Res 6: 184-187

40. West KM (1978) Specific morbid effects (complications). In: KM West (ed) Epidemiology of diabetes and its vascular lesions. Elsevier North-Holland, New York, pp 351-439

41. Eschwege E, Lacroux A, Papoz L, Fontbonne A, Costagliola D (1989) Epidemiology of complications of NIDDM. In: KGMM Alberti, R Mozze (eds) Frontiers of diabetes research; current trends in non insulin-dependent diabetes mellitus. Elsevier Science Publishers BV (Biomedical division), New York, pp 71-87

42. Mogensen CE (1988) Management of diabetic renal involvement and disease. Lancet I: 867

43. Chase HP, Jackson WE, Hoops SL, Cockerham RS, Archer PG, O'Brien D (1989) Glucose control and the renal and retinal complications of insulin-dependent diabetes. JAMA 261: $1155-1160$

44. Mills JL, Simpson JL, Driscoll SG et al. (1988) Incidence of spontaneous abortion among normal women and insulin-dependent diabetic women whose pregnancies were identified within 21 days of conception. N Engl J Med 319: 1617-1623

45. Job D, Eschwege E, Guyot-Argenton Cl, Aubry JP, Tchobroutsky G (1976) Effect of multiple daily insulin injections of the course of diabetic retinopathy. Diabetes 25:463-469

46. Basdevant A, Costagliola D, Lanoe JL, Goldgewicht C, Triomphe A, Metz F, Denys H, Eschwege E, Fardeau M, Tchobroutsky $G$ (1982) The risk of diabetic control: a comparison of hospital versus general practice supervision. Diabetologia 22: 309-314

Prof. Georges Tchobroutsky

Service de Diabetologie

Hôtel-Dieu

1, place du Parvis Notre-Dame

F-75181 Paris Cedex O4

France 